\title{
The Cervical Sequestrated Disc Fragment Presenting as Mass Lesion: Case Report and Review of the Literature
}

\author{
Ali Babashahi ${ }^{1}$, Morteza Taheri ${ }^{2 *}$ \\ ${ }^{1} \mathrm{MD}$, Assistant Professor of Neurosurgery, Iran University of Medical Sciences, Rasool-e Akram Hospital, Tehran, Iran \\ ${ }^{2}$ MD, Resident of Neurosurgery, Iran University of Medical Sciences, Rasool-e Akram Hospital, Tehran, Iran \\ * Corresponding Author Address: Department of Neurosurgery, Rasool-e Akram Hospital, Niyayesh Street, Sattarkhan Street, Tehran, Iran. \\ Tel:+989120194908,+982166503890. Fax:+982166509120. Email:drtaheri38@yahoo.com.
}

\section{Abstract}

Background \& Importance: Disc herniation is defined as the prolapsed of material disc into the spinal canal. If the disc fragment is free in spinal canal, it is called sequestration disc fragment. Occasionally, alteration in sequestration disc fragment makes the diagnosis of the disc herniation, challenging.

Case Presentation: We reviewed a rare case of the cervical sequestrated disc herniation mimicking a spinal canal extradural abscess. The 55-year-old man presented cervical axial and radicular pain. Cervical spine MRI showed an extra-axial longitudinal mass behind C5 and C6 vertebral body association with anterior compression on cord. In T2 images of lesion, the signal intensity varied from isointense to hyperintense and marked peripheral enhancement with GD injection. After unilateral right C6 hemilaminectomy, a sequestrated disc fragment was resected from epidural space.

Conclusion: The histopathologic findings were in favor of sequestrated disc herniation. Although MRI is the main preoperative diagnostic tool for accurate diagnosis of the sequestrated disc herniation, the sequestrated disc fragment can show the variable features on MRI and can be misdiagnosed with the other space-occupying lesions.

Keywords: Cervical Disc Herniation; Sequestrated Disc Fragment; Mass Lesion

Please cite this paper as: Babashahi A, Taheri M. The Cervical Sequestrated Disc Fragment Presenting as Mass Lesion: Case Repoert and Review of the Literature. Iran. J. Neurosurg. 2016;2(2):24-29

\section{Background and Importance}

Cervical disc herniation is one of the most common causes of cervical pain and limb neurologic deficit (1). Disc herniation is defined as the prolapsed of material disc into the spinal canal (2). In the cervical region, it occurs more commonly in the postrolateral (2). The herniated disc can take the form of protrusion, extrusion and sequestration (2). When disc fragment is connected to intervertebral disc and contain Annulus, not connected to intervertebral disc and only contain posterior longitudinal ligament (PLL) and when is free within spinal canal called protrusion, extrusion and sequestration, respectively (2). The sequestrated disc herniation can migrate rostral, caudal and lateral direction commonly and to posterior, in rare cases $(1,3)$. MRI can be a useful and reliable tool in diagnosis of disc herniation disease (2) because of its availability in most regions. Unusual cervical sequestrated disc herniation mimicking other pathologies is a very rare situation (4). Occasionally, alteration in sequestration disc fragment makes the diagnosis of the disc herniation challenging. Therefore, the sequestrated disc fragment can mimic other pathologies and differential diagnoses including tumoral mass, abscess, cyst and even hematoma $(4,5)$. In this study, we review a rare case of the cervical sequestrated disc herniation mimicking a spinal canal extradural abscess.

\section{Case Presentation}

A 55-year-old man was admitted with cervical axial and radicular pain in the right $\mathrm{C} 6$ root from 6 months ago. Physical examination showed mild weakness in the right distal muscles force, hypoesthesia in the right C6 root and generalized hyper-reflexia. The cervical spine MRI showed an extra-axial longitudinal mass behind $\mathrm{C} 5$ and $\mathrm{C} 6$ vertebral body association with anterior compression on cord. It was isointense to hyperintense on T2 and showed marked peripheral enhancement after GD injection (Figure 1). The cell blood Count (CBC), ESR and CRP were reported normal. Medical and conservative treatment failed and patient was candidate for surgical resection. The differential diagnoses included abscess, spinal canal extra-dural tumor and metastasis. The posterior approach with unilateral right C6 hemilaminectomy was done. Under surgical magnification, a sequestrated disc fragment was resected from epidural space. There was no evidence of pus or infectious process and no tumoral mass. The post-operative MRI showed no residual fragment (Figure 2). The patient muscle force improved gradually but the pain and hypoesthesia relief after surgery. The histopathologic findings were in favor of sequestrated disc herniation.

\section{Discussion}

The sequestration disc herniation occurs in rare cases and can migrate to rostral, caudal and lateral direction (1). Although MRI 

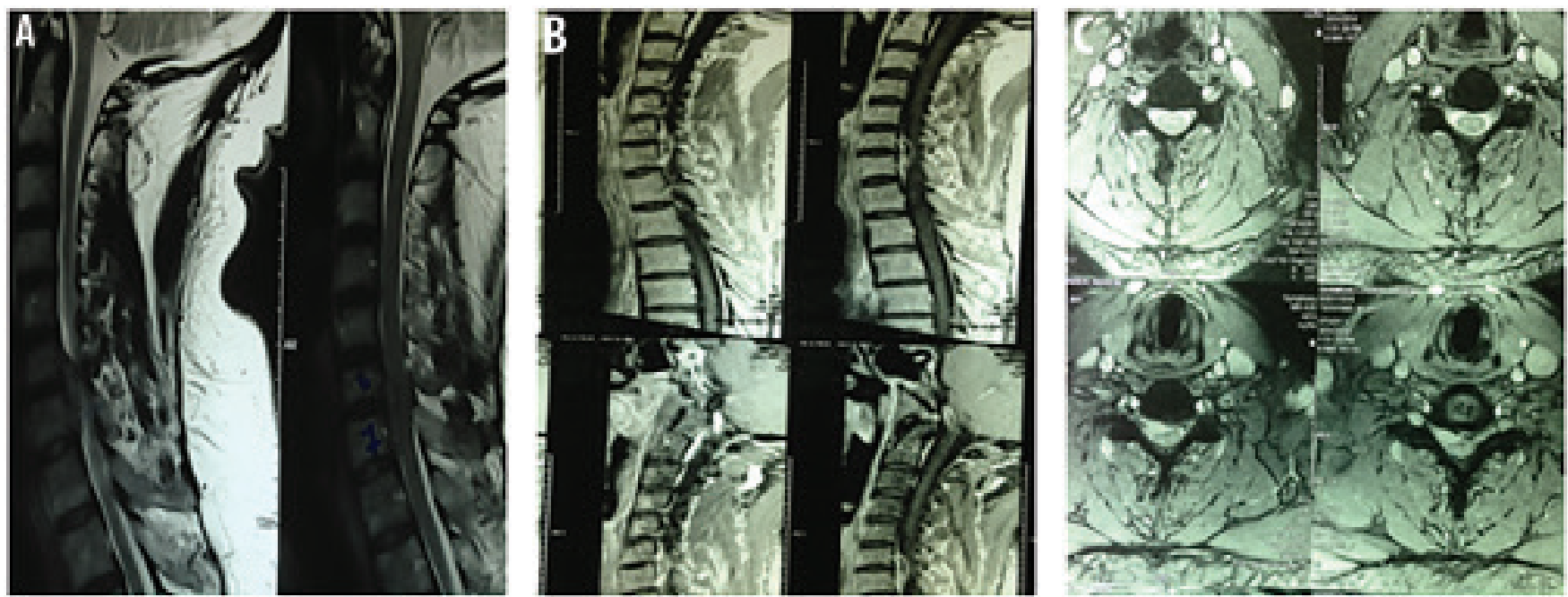

Figure 1. A) Sagittal T2, B) Sagittal T1 with GD Injection and C) Axial T2 Sequences Show Epidural Lesion

is the best diagnostic tool in the cases of disc herniation, in some cases of the sequestrated disc fragment, the diagnosis can be confused with other pathologies and other occupying, mass lesion and only surgery can lead to the exact diagnosis $(3-5,6,7)$. The differential diagnosis includes abscess and infections, benign and malignant neoplasm, metastasis as well as cyst.

In the present study, we reported a 55 year-old man, suffering from radicular pain and mild weakness. The MRI showed a mass lesion, located in the epidural space of the posterior of C6 and C7 vertebral body and intervertebral space, longitudinally. The lesion was iso-signal intensity on T2 image sequence and marked peripheral enhancement on GD injection image sequence. Our primary diagnosis was epidural abscess because of the significant mass lesion, presence of mass without relation to intervertebral disc material and MRI findings. The differential diagnosis included abscess, metastasis, and other neoplasm and sequestrated disc herniation. During surgery, we observed a fibrosis disc fragment that was free in the epidural space without any relation to the intervertebral disc material and also there was no evidence of abscess or neoplasm. The histological findings were in favor of the sequestrated disc fragment. This situation is rare and only few studies reported similar finding.

Srinivasan et al. suggested that nontraumatic sequestrated disc fragment migrating to the epidural space is a rare disease and found only 10 cases in the literatures (1).

Nievas and Hoellerhage analyzed 3000 patients and demonstrated that only 11 patients presented an unusual sequestrated disc fragment. The differential diagnosis in their patients included abscess, hematoma, synovial cyst, and various neoplasms. In only one of the 11 patients, the disease occurred in the cervical region and the others presented in dorsal and lumbar region. They reported a 72 year-old man with a mass in intradural space compressing the cord at the level of C6C7. The lesion was hypersignal on T2-weighted images and showed peripheral enhancement after GD injection. The initial diagnosis was teratoma and an old capsulated hematoma (8).

Rosenberg reported two cases of the cervical disc herniation, presented as an epidural mass in the posterior of the odontoid process. The initial symptom in his report was extradural mass lesion (9).

Stavrinou et al. reported a case of cervical disc herniation that was misinterpreted with the nerve sheath tumor. Their patient refused surgery, but within seven weeks, her symptoms improved and the mass lesion vanished on MRI. The final diagnosis was the cervical disc herniation (6). Ashizawa reported a case of calcified sequestrated disc herniation at C4-C5 level. MRI demonstrated a large extradural mass compressing the spinal cord and had slightly high intensity on both T1- and T2-weighted images. A low intensity rim at the periphery of the mass on axial T1-weighted is seen in the images (10).

Another study performed by Tofuku and colleagues reported a case with the oval mass lesion in the epidural space at the level of C7. The lesion was iso-signal on T1-weighted images and hypersignal on T2-weighted images and peripheral enhancement on T1-weighted images with GD injection (11).

Joaquim et al. reported a 66-year-old man presented with a well defined mass, compressing the dural sac at the level of C7. The lesion was isointense on T1-weighted images and heterogeneously hyperintense on T2-weighted and showed peripheral enhancement after GD injection. A diagnosis of extramedullary lesion was done. As a result, the differential diagnosis included epidural hematoma, epidural abscess, synovial cysts, epidermoid cysts, and extradural tumor (12).

\section{Review of Literature}

After search for the sequestrated disc fragment mimicking extradural tumor and its synonyms, we found 51 English articles related to this issue. These articles reported 88 cases of the sequestrated disc fragment mimicking other pathologies. In 22 cases, the sequestrated disc fragment mimicked other pathologies, but excluded because the sequestrated disc fragment was the initial preoperative diagnosis. Two cases were excluded due to the sequestrated disc fragment as the initial diagnosis, but final diagnoses were epidural abscess and hematoma $(13,14)$. Three cases were excluded for the absence of enough data and also nine patients because of the sequestrated disc fragment migrated to intradural space. We surveyed other 52 patients as well, 37 cases were male and 15 female. The mean age was $53 \pm 90$ with a range of 28 to 83 years old. From a total of 52 patients, sequestrated disc fragment occurred in lumbosacral, dorsal and cervical region, in 40, 6 and 6 patients, respectively. The sequestrated disc fragment migrated to anterior, lateral, anterolateral, posterior and 

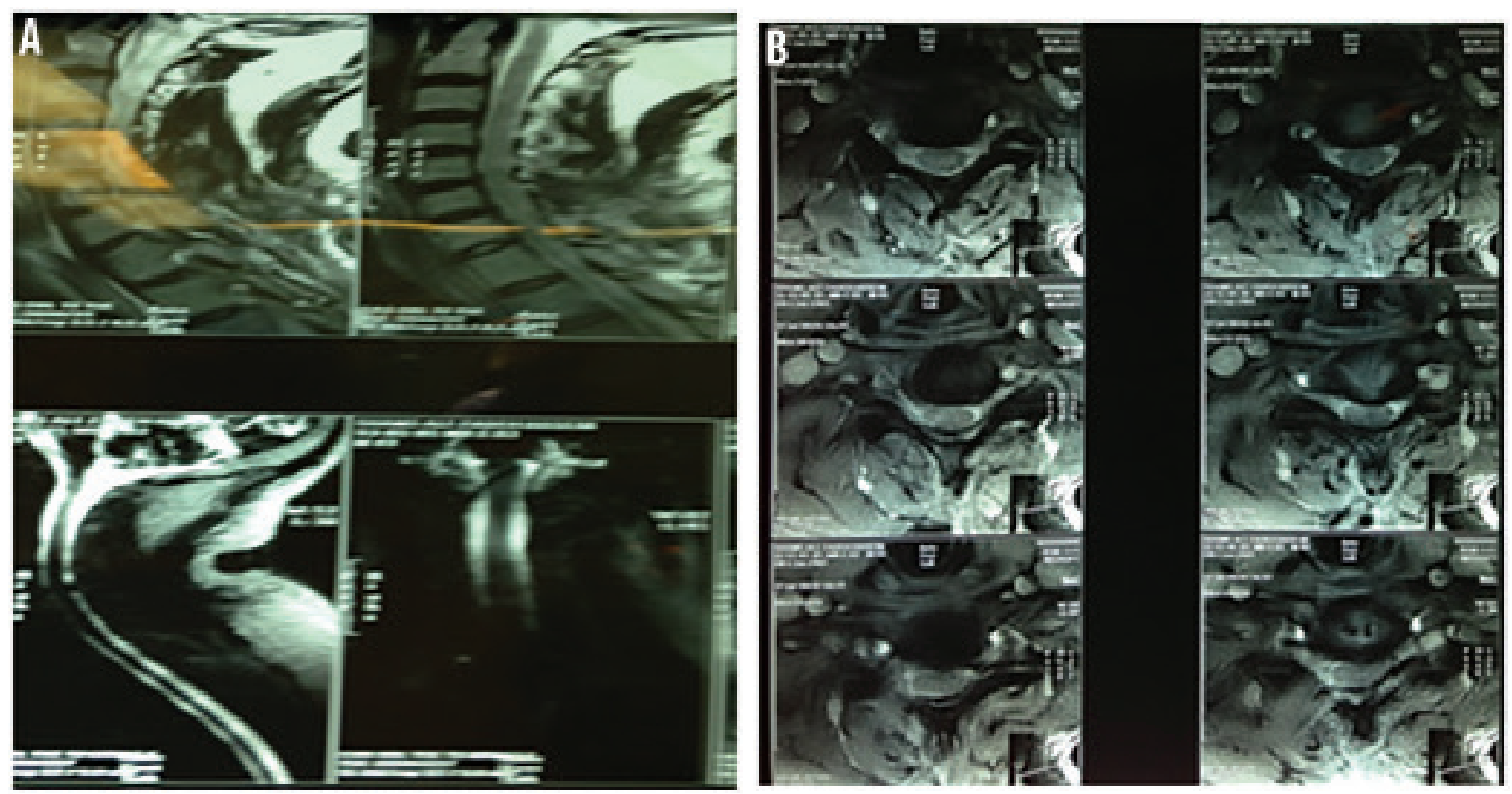

Figure 2. Postoperative MRI Demonstrating no Residual Mass: A) Sagittal View and B) Axial View.

postrolateral direction in $6,3,1,22$ and 19 patients, respectively. In one patient, the location of sequestrated disc fragment was unclear. The diagnostic survey was CT scan in three patients and MRI in other 49 patients. The T1-weighted images showed sequestrated disc fragment hypo, iso, hyper and iso-to-hyper signal intensity in 13, 7, 3 and 1 patients, respectively. The sequestrated disc fragment was hypo, iso, hyper, iso-to-hyper and heterogeneous signal intensity on the T2-weighted images in 10,1,16,1 and 3 patients, respectively. After GD injection, the lesion demonstrated the peripheral rim enhancement in 30 patients, heterogeneous enhancement in one patient and diffuse enhancement in one patient. In one patient, the lesion showed no enhancement and in one patient, MRI was done with no injection due to renal problems. The lesion of two patients, revealed enhancement but no more information were reported. Finally, the initial preoperative diagnosis was nerve sheath tumor in 1 , dumbbell shape tumor in 1 , facet cyst in 1 , metastasis in 1 , cystic tumor in 4 and synovial cyst in 3 patients. The other 41 patients, the initial diagnosis was epidural mass lesion (the differential diagnosis included abscess, hematoma, extradural benign and malignant neoplasm). Table 1 summarizes the most important data of these 53 patients.

\section{Conclusion}

Preoperatively, MRI is the outstanding diagnostic tool for accurate diagnosis of the sequestrated disc herniation which shows varying features on MRI and can make diagnoses very difficult. It is sometimes misdiagnosed with similar space-occupying lesions. In a case with peripheral enhanced mass lesion in the epidural space, the diagnosis of a sequestrated disc fragment should be considered in the differential diagnosis.

\section{Acknowledgement}

The authors appreciate Clinical Research Development Unit of Rasool-e Akram Hospital, Tehran, Iran for their technical supports for implementation of the project and help in English editing of the manuscript.

\section{Funding}

None.

\section{Conflicts of Interest}

The authors declare that they have no conflicts of interest.

\section{Authors' Contribution}

Data collection: Ali Babashahi. Morteza Taheri. Drafting the article: Morteza Taheri 
Table 1. The Most Important Features of the Reported Cases

\begin{tabular}{|c|c|c|c|c|c|c|c|c|c|}
\hline Study & Age & Sex & Level & Migration & Location & T1 & $\mathbf{T 2}$ & GD Injection & Initial Diagnosis \\
\hline Rosenberg, et al 1991(9) & 74 & $\mathrm{~F}$ & $\mathrm{C} 2$ & Anterior & Extradural & - & - & - & Neoplasm \\
\hline Rosenberg, et al 1991(9) & 82 & $\mathrm{~F}$ & $\mathrm{C} 2$ & Anterior & Extradural & - & - & - & Neoplasm \\
\hline Ashizawa, et al(10) & 57 & $\mathrm{M}$ & $\mathrm{C} 4-5$ & Anterior & Extradural & Hyper & Hyper & - & Extradural Mass \\
\hline Stavrinou, et al 2009(6) & 46 & $\mathrm{~F}$ & $\mathrm{C} 5-6$ & Anterior & Extradural & Нуро & - & $\begin{array}{c}\text { Marked } \\
\text { Heterogeneous } \\
\text { Enhancement }\end{array}$ & Nerve Sheath Tumor \\
\hline Tofuku, et al 2007(11) & 72 & M & $\mathrm{C} 7$ & Postrolateral & Extradural & Iso & $\begin{array}{l}\text { Hyper } \\
\text { (Heteroge- } \\
\text { neous) }\end{array}$ & $\begin{array}{c}\text { Peripheral } \\
\text { Enhancement }\end{array}$ & $\begin{array}{l}\text { Epidural Hematoma, } \\
\text { Epidural Abscess, } \\
\text { Synovial Cysts, } \\
\text { Epidermoid Cysts, and } \\
\text { Extradural Tumor }\end{array}$ \\
\hline Joaquim, et al 2010(12) & 66 & M & $\mathrm{C} 7$ & Posterior & Extradural & Iso & $\begin{array}{l}\text { Hyper- } \\
\text { (Heteroge- } \\
\text { neous) }\end{array}$ & $\begin{array}{c}\text { Peripheral } \\
\text { Contrast } \\
\text { Enhancement }\end{array}$ & $\begin{array}{c}\text { Extramedullary Lesion } \\
\text { (Epidural Hematoma, } \\
\text { Epidural Abscess, } \\
\text { Synovial Cysts, } \\
\text { Epidermoid Cysts, and } \\
\text { Extradural Tumor) }\end{array}$ \\
\hline Sasaki, et al 2005(15) & 37 & M & $\mathrm{T} 2-3$ & Posterolateral & Extradural & - & - & $\begin{array}{c}\text { Slight } \\
\text { Enhancement }\end{array}$ & $\begin{array}{l}\text { Epidural Hematoma, } \\
\text { Abscess or Thoracic } \\
\text { Disc Herniation }\end{array}$ \\
\hline $\begin{array}{c}\text { Neugroschl, et al } \\
1999(16)\end{array}$ & 47 & M & $\mathrm{T} 7-8$ & Postrolateral & Extradural & Нуро & Hyper & $\begin{array}{c}\text { Rim } \\
\text { Enhancement }\end{array}$ & Mass Lesion \\
\hline $\begin{array}{l}\text { Miyakoshi, et al } \\
\text { 2013(17) }\end{array}$ & 53 & M & T9-10 & Posterior & Extradural & Iso & Hyper & $\begin{array}{c}\text { Peripheral } \\
\text { Contrast } \\
\text { Enhancement }\end{array}$ & Mass Lesion \\
\hline Kim, et al 2008(18) & 66 & M & T10-11 & Posterior & Extradural & Нyро & Hyper & $\begin{array}{c}\text { Rim } \\
\text { Enhancement } \\
\end{array}$ & Mass Lesion \\
\hline Partheni, et al 2005(19) & 55 & M & $\mathrm{T} 10-11$ & Posterior & Extradural & - & Iso & - & Extramedullary Lesion \\
\hline Bose, et al 2003(20) & 54 & M & T11-12 & Anterior & Extradural & Нуро & $\begin{array}{c}\text { Hyper } \\
\text { (Heteroge- } \\
\text { neous) }\end{array}$ & $\begin{array}{l}\text { Peripheral } \\
\text { Enhancement }\end{array}$ & Mass Lesion \\
\hline Derincek, et al 2009(3) & 60 & $\mathrm{~F}$ & L1-2 & Postrolateral & Extradural & Iso & Hyper & $\begin{array}{c}\text { Peripheral Rim } \\
\text { Enhancement }\end{array}$ & Large Epidural Mass \\
\hline $\begin{array}{c}\text { Dimogerontas, et al } \\
\text { 2012(4) }\end{array}$ & 56 & M & L1-4 & Lateral & Extradural & Iso & Hyper & $\begin{array}{c}\text { Peripheral Rim } \\
\text { Enhancement }\end{array}$ & Tumor-like Lesion \\
\hline Ju, et al 2012(21) & 74 & M & L2-3 & Postrolateral & Extradural & - & Нypo & $\begin{array}{c}\text { Peripheral Rim } \\
\text { Enhancement }\end{array}$ & Mass Lesion \\
\hline Yoo, et al 2015(22) & 32 & M & L2-3 & Posterior & Extradural & - & $\begin{array}{c}\text { Hyper } \\
\text { (Heteroge- } \\
\text { neous) }\end{array}$ & 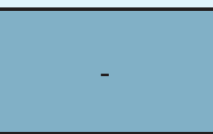 & Intraspinal Facet Cyst \\
\hline Nievas, et al 2009(8) & 45 & $\mathrm{~F}$ & L2-3 & Anterolateral & Extradural & - & Нуро & $\begin{array}{c}\text { Peripheral } \\
\text { Enhancement }\end{array}$ & Abscess \\
\hline $\begin{array}{c}\text { Neugroschl, et al } \\
1999(16) \\
\end{array}$ & 57 & M & L2-3 & Posterior & Extradural & Нyро & Hyper & $\begin{array}{c}\text { Rim } \\
\text { Enhancement } \\
\end{array}$ & Epidural Lesion \\
\hline $\begin{array}{l}\text { Gonçalves, et al } \\
2010(23)\end{array}$ & 51 & M & L2-3 & Postrolateral & Extradural & Нyро & Hyper & No Injected & $\begin{array}{l}\text { Epidural Hematoma, } \\
\text { Epidural Empyema, } \\
\text { Nerve Sheath Tumor } \\
\text { and Meningioma } \\
\text { and Posterior Disc } \\
\text { Migration } \\
\end{array}$ \\
\hline Lichtor 1989(24) & 61 & M & L2-3 & Posterior & Extradural & Iso & - & - & Epidural Mass \\
\hline Bonaroti, et al 1998(25) & 51 & M & L2-3 & Posterior & Extradural & Нyро & Нуро & $\begin{array}{c}\text { Peripheral Rim } \\
\text { Enhancement }\end{array}$ & $\begin{array}{c}\text { Abscess. Hematoma or } \\
\text { Neoplasm }\end{array}$ \\
\hline
\end{tabular}


Cervical Disc Fragment, Presenting as Mass Lesion

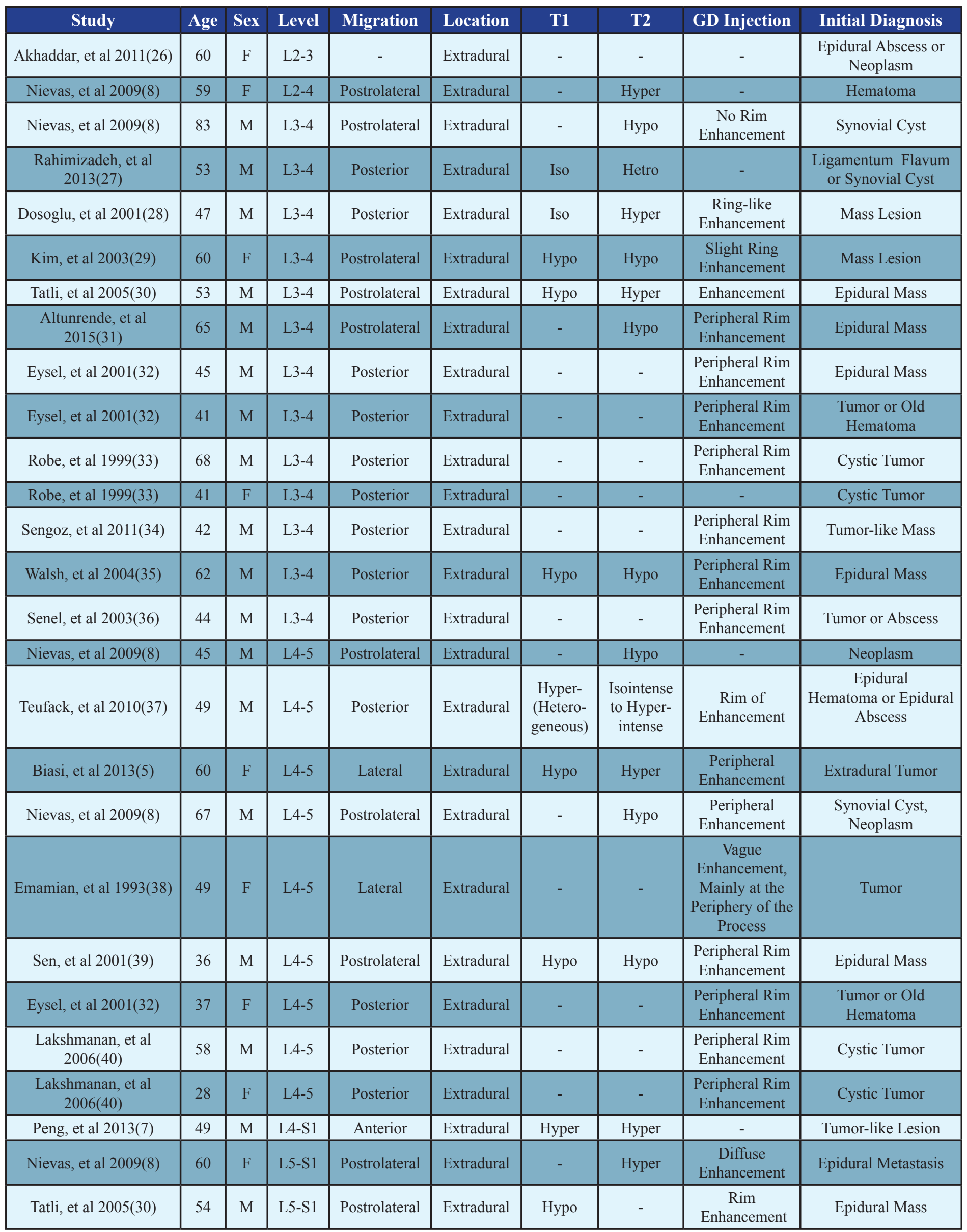




\begin{tabular}{|c|c|c|c|c|c|c|c|c|c|}
\hline Study & Age & Sex & Level & Migration & Location & T1 & T2 & GD Injection & Initial Diagnosis \\
\hline El Asri, et al 2008(41) & 42 & M & L5-S1 & Postrolateral & Extradural & - & - & - & Epidural Mass \\
\hline El Asri, et al 2008(41) & 36 & M & L5-S1 & Posterior & Extradural & - & - & - & Epidural Mass \\
\hline Saruhashi, et al 1999(42) & 44 & F & L5-S1 & Postrolateral & Extradural & - & - & - & $\begin{array}{c}\text { Dumbbell-shape } \\
\text { Tumor }\end{array}$ \\
\hline Sakas, et al 1995(43) & 70 & M & L5-S1 & Postrolateral & Extradural & - & - & - & Synovial Cyst \\
\hline
\end{tabular}

\section{References}

1. Srinivasan US, Kumar GS, Mahesha KB. Posterior epidural migration of sequestrated cervical disc fragment: case series. Asian Spine Journal. 2011;5(4): 220-7.

2. Morshed T, Haque S, Awwal A, Abedin N, Sultana S. Role of Magnetic Resonance Imaging in the Diagnosis of Cervical Disc Herniation: Comparison with Peroperative Findings. Chattagram Maa-O-Shishu Hospital Medical College Journal. 2014;13(2):59-62.

3. Derincek A, Ozalay M, Sen O, Pourbagher A. Posterior epidural mass: can a posteriorly migrated lumbar disc fragment mimic tumour, haematoma or abscess? Acta Orthopaedica Belgica. 2009;75(3):423-7.

4. Dimogerontas G, Paidakakos NA, Konstantinidis E. Voluminous free disk fragmen mimicking an extradural tumor. Neurologia medico-chirurgica. 2012;52(9):656-8.

5. Biasi PR, Mallmann AB, Crusius PS, Seibert CA, Crusius MU, Crusius CU, Et al Sequestered lumbar disc herniation mimicking spinal tumor. Arquivos Brasileiros de Neurocirurgia. 2013;32(4):268-70.

6. Stavrinou LC, Stranjalis G, Maratheftis N, Bouras T, Sakas DE. Cervical disc, mimicking nerve sheath tumor, with rapid spontaneous recovery: a case report. Eurpian Spine Journal.2009;18 Supplement 2:176-8.

7. Peng B, Pang X. Tumour-like lumbar disc herniation. BMJ Case Rep 2013. doi:10.1136/bcr-2013-009358.

8. Carviy Nievas MN, Hoellerhage HG. Unusual sequestered disc fragments simulating spinal tumors and other space-occupying lesions. Clinical article. Journal of Neurosurgical Spine.2009;11(1):42-8.

9. Rosenberg WS, Rosenberg AE, Poletti CE. Cervical disc herniation presenting as a mass lesion posterior to the odontoid process. Report of two cases. Journal of Neurosurgery. 1991;75(6): 954-9.

10. Ashizawa K, Uetani M, Okimoto T, Hayashi K, ETO M. Epidural Calcified Sequestration of Cervical Intervertebral Disk. Acta medica Nagasakiensia. 1999, 44(1-2): 58-60

11. Tofuku K, Koga H, Kawabata N, Yuasa S, Yone K, Komiya S. Dorsally sequestered cervical disc herniation. Spine (Phila Pa 1976). 2007; 32(26):E837-40. 12. Joaquim AF, Ghizoni E, Cabral SR, Hamilton DK, Shaffrey CI. Unusua Presentation of Sequestered Cervical Disc Herniation. Jornal Brasileiro De Neurocirurgia. 2010;21(4):239-41.

13. Watanabe N, Ogura T, Kimori K, Hase H, Hirasawa Y. Epidural hematoma of the lumbar spine, simulating extruded lumbar disk herniation: clinical, discographic and enhanced magnetic resonance imaging features. A case report. Spine (Phila Pa 1976). 1997;22(1):105-9.

14. Bakar B, Tekkok IH. Lumbar periradicular abscess mimicking a fragmented lumbar disc herniation:an unusual case. Journal of Korean Neurosurgical Society. 2008;44(6):385-8.

15. Sasaki S, Kaji K, Shiba K. Upper thoracic disc herniation followed by acutely progressing paraplegia. Spinal Cord. 2005;43:741-5.

16. Neugroschl C, Kehrli P, Gigaud M, Ragragui O, Maitrot D, Manelfe C, et al. Posterior extradural migration of extruded thoracic and lumbar disc fragments: role of MRI. Neuroradiology. 1999; 41(9):630-5.

17. Miyakoshi N, Hongo M, Kasukawa Y, Ishikawa Y, Shimada Y. Posteriorly migrated thoracic disc herniation: a case report. Journal of Medical Case Reports. 2013;7:41.

18. Kim IS, Lee SW, Son BC, Sung JH. Posterior epidural migration of thoracic disc fragment. Journal of Korean Neurosurgical Society. 2008;43(5):239-41.

19. Partheni M, Fratzoglou M, Kalogeropoulou C, Zabakis P, Panagiotopoulos V, Konstantinou D. Dorsal extradural thoracic disc fragment: a diagnostic challenge. Journal of spinal disorders \& techniques. 2005;18(6):544-6.

20. Bose, B.Thoracic extruded disc mimicking spinal cord tumor. Spine Journal. 2003; 3(1):82-6.

21. Ju JH, Kim HW, Jung CK, Ha HG. Sudden onset of cauda equina syndrome resulting from posterior migration of lumbar herniated disc without significant previous neurological signs. Korean Journal of Spine. 2012; 9(3):281-4.

22. Yoo YS, Ju CI, Kim SW, Kim DM. Posterior epidural migration of an extruded lumbar disc mimicking a facet cyst: a case report. Korean Journal of Spine. 2015; 12(1):12-4

23. Goncalves FG, Hanagandi PB, Torres CI, O’Donovan RD. Posterior migration of lumbar disc herniation - imaging dilemma due to contrast contraindication: a case report. Radiologia Brasileira. 2010. 45(3):170-2.

24. Lichtor, T. Brief Communication Posterior Epidural Migration of Extruded umbar Disk. Surgical Neurology. 1989·32:311-2.

25. Bonaroti EA, Welch WC, Posterior epidural migration of an extruded lumbar disc fragment causing cauda equina syndrome. Clinical and magnetic resonance imaging evaluation. Spine (Phila Pa 1976). 1998; 23(3):378-81.

26. Akhaddar A, El-Asri A, Boucetta M. Posterior epidural migration of a lumbar disc fragment: a series of 6 cases. Journal of Neurosurgery Spine. 2011; 15(1):117-28

27. Rahimizadeh AB, Soufiani H, Rahimizadeh AV. Posterior epidural migration of sequestered lumbar disc fragment causing cauda equina syndrome. Coluna/Columna. 2013;12(1):78-80.

28. Dosoglu M, Is M, Gezen F, Ziyal MI. Posterior epidural migration of a lumbar disc fragment causing cauda equina syndrome: case report and review of the relevant literature. Eurpian Spine Journal. 2001;10(4): 348-51.

29. Kim MS, Hur JW, Lee JW, Lee HK. Posterior and Lateral Epidural Migration of Extruded Lumbar Disc Fragments - Case Report . Journal of Korean Neurosurgical Society. 2003;33:297-8.

30. Tatli M, Guzel A, Ceviz A, Karadag O. Posterior epidural migration of sequestered lumbar disc fragment causing cauda equina syndrome. British Journal of Neurosurgery. 2005;19(3):257-9.

31. Altunrende ME, Akcakaya MO, Posterior epidural lumbar disc fragment mimicking epidural mass, The Spine Journal. 2015, doi: 10.1016/j.spinee.2015.06.027. 32. Eysel P, Herbsthofer B. Dorsal compression of the epidural cord due to free sequestral lumbar prolapse. Diagnostic problems in magnetic resonance imaging and computed tomography. Archive of Orthopeidc Trauma Surgery. 2001;121(4):238-40. 33. RobeP, Martin D, Lenelle J, Stevenaert A. Posterior epidural migration of sequestered lumbar disc fragments. Report of two cases. Journal of Neurosurgery.1999;90(2 Suppl):264-6.

34. Sengoz A, Kotil K, Tasdemiroglu T. Posterior epidural migration of herniated lumbar disc fragment Clinical article. Journal of Neurosurgery: Spine. 2011;14:313-7.

35. Walsh AJ, Martin Z, McCormack D. Cauda equina syndrome secondary to posterior epidural migration of a lumbar disc fragment: a rare phenomenon. European Journal of Orthopaedic Surgery \& Traumatology. 2004;14:30-1.

36. Senel A, Cokluk C, Celik F. Posterior Epidural Migration of Extruded Lumbar Disc Mimicking Epidural Mass: Case Report. Turkish Neurosurgery. 2003;13:115-7.

37. Teufack SG, Singh H, Harrop J, Ratliff J. Dorsal epidural intervertebral disk herniation with atypical radiographic findings: case report and literature review. The Journal of Spinal Cord Medicine. 2010; 33(3): 268-71.

38. Emamian SA, Skriver EB, Henriksen L, Cortsen ME. Lumbar herniated disk mimicking neurinoma case report. Acta Radiologica. 1993;34(2):127-9.

39. Sen O, Aydin V, Erdogan B, Yildirim T, Caner H. Cauda Equina Syndrome Caused by Posterior Epidural Migration of an Extruded Lumbar Disc Fragment. Turkish Neurosurgery. 2001;11:108-10.

40. Lakshmanan P, Ahuja S, Lyons K, Howes J, Davies PR. Sequestrated lumbar intervertebral disc in the posterior epidural space: a report on two cases and review of the literature. Spine Journal. 2006; 6(5):583-6.

41. El Asri AC, Naama O, Akhaddar A, Gazzaz M, Belhachmi A, Mostarchid BE, et al. Posterior epidural migration of lumbar disk fragments: report of two cases and review of the literature. Surgical Neurology. 2008;70(6): 668-71.

42. Saruhashi Y, Omura K, Miyamoto K, Katsuura A, Hukuda S. A migrated lumbar disc herniation simulating a dumbbell tumor. Journal of Spinal Disorders. 1999;12(4):307-9. 